\title{
Procesos y retos en torno al patrimonio y a los paisajes culturales: una reflexión teórica desde la geografía española'
}

\author{
Processes and challenges regarding heritage and \\ cultural landscapes: a theoretical reflection \\ from Spanish geography
}

\author{
María del Carmen Cañizares Ruíz²
}

\begin{abstract}
RESUMEN
La temática que surge de la unión del análisis del patrimonio, tal y como lo entendemos en la actualidad en su vertiente territorial, así como del paisaje, principalmente en lo referido a su enfoque patrimonial y a los paisajes culturales, ha sido una de las más atractivas e interesantes para los geógrafos españoles en los últimos años. En un contexto marcado por el protagonismo del territorio en el cambio de siglo, se realiza una revisión de las principales aportaciones de la geografía en España tanto en relación con el patrimonio, como con el territorio y sus paisajes, para llegar al análisis geográfico de los paisajes culturales. Reflexión teórica que puede servir de apoyo a geógrafos de otros ámbitos territoriales como es el caso de América Latina.
\end{abstract}

Palabras clave: Patrimonio, Paisaje, Paisajes Culturales, Paisajes Patrimoniales.

\begin{abstract}
The theme that arises from the union of the analysis of heritage, as we understand it nowadays in its territorial aspect, as well as the landscape, mainly in relation to its patrimonial approach and cultural landscapes, has been one of the most attractive and interesting for Spanish geographers in recent years. In a context marked by the prominence of the territory at the turn of the century, a review is made of the main contributions made from geography in Spain both in relation to heritage, as with the territory and its landscapes, in order to reach geographical analysis of cultural landscapes. This theoretical reflection can be used to support geographers from other territorial areas, such as Latin America.
\end{abstract}

Key words: Heritage, Landscape, Cultural Landscapes, Heritage Landscapes.

Recibido 5 abril 2019; Aceptado 13 agosto 2019; versión de preimpresión 
La unión de los conceptos de patrimonio y paisaje, así como su resultado más evidente en el marco territorial, los paisajes culturales, ha sido una temática reciente en la geografía española. Su indudable atractivo, en un contexto de demanda de atención hacia el territorio, ha despertado el interés de los geógrafos y ello se ha reflejado en numerosas publicaciones, contribuciones a congresos, proyectos de investigación, etc. A continuación, abordaremos, inicialmente, el concepto de patrimonio, su ampliación, y su interés geográfico con atención al patrimonio territorial para, después, analizar el protagonismo del territorio y sus paisajes, con especial atención hacia algunas aportaciones institucionales como el Convenio Europeo del Paisaje (Consejo de Europa, 2000). Finalmente, nos adentraremos en el análisis de los paisajes culturales, de gran significado dada su capacidad para crear marcos de vida que presentan gran interés geográfico en relación con calidad territorial.

Las preguntas de investigación son las siguientes: ¿cómo han sido abordados los conceptos de patrimonio, paisaje y paisajes culturales por los geógrafos españoles? y ¿qué retos afronta el geógrafo en España en el estudio de los paisajes culturales y/o patrimoniales?. Por su parte, el objetivo principal es realizar una reflexión teórica sobre los procesos y retos que han consolidado esta temática durante las últimas décadas en España a partir de los cambios derivados del giro cultural en las ciencias sociales (cultural turn) y puntualmente en geografía, relacionado con el papel de la cultura en todos los dominios de esta ciencia (Claval, 2001: 11; Fernández Christlieb, 2006: 221). Revisión extensa que pretende incorporar los avances teóricos y metodológicos realizados en relación con el patrimonio y, sobre todo, con el paisaje para concluir en el estudio de los paisajes culturales y cómo son abordados por esta disciplina.

La metodología empleada se basa en la revisión bibliográfica de las aportaciones más relevantes, de distinto tipo (conceptuales,...), realizadas por los geógrafos españoles, especialmente en el cambio de siglo cuando se intensifican las publicaciones en relación con el patrimonio y el paisaje. Revisión en la que son fundamentales las referencias de geógrafos especialistas en paisaje como Eduardo Martínez de Pisón (2007, 2012), Florencio Zoido Naranjo (2010, 2012), Joan Nogué i Font (2010) y Rafael Mata Olmo $(2008,2014)$, entre otros, así como publicaciones de importancia en el caso del Atlas de los Paisajes de España (Mata y Sanz, 2003); junto con textos de geógrafos que abordan el análisis del patrimonio y los paisajes de distinta tipología (urbanos, agrarios, industriales,...) como Miguel Ángel Troitiño Vinuesa (1998, 2010), Horacio Capel Saez (2014), José Ortega Valcárcel (1998), Víctor Fernández Salinas y Rocío Silva Pérez $(2015,2016)$ o la que suscribe M. Carmen Cañizares Ruiz $(2010,2014)$. Igualmente se profundiza en la contribución a este marco teórico de publicaciones recientes como la obra Los Paisajes Patrimoniales de España coordinada por Fernando Molinero Hernando y Joan Tort Donada (2018). Además, se incorporan las aportaciones documentales de los principales convenios, cartas y acuerdos realizados a diferentes escalas en relación con estas temáticas: en el contexto internacional (convenios de la Unesco, la Lista del Patrimonio Mundial), en la escala europea (Convenio Europeo del Paisaje, Convenio de Faro) y en España (Plan Nacional de Paisaje Cultural), claves para consolidar un marco teórico que permite al geógrafo adentrarse en la unión patrimonio/paisaje.

Los resultados de la revisión de todas estas aportaciones, principalmente las realizadas desde la geografía en España, se concretan en una puesta al día de lo que ofrece esta temática en el momento actual, y pueden servir de apoyo teórico a los geógrafos de otros contextos territoriales, especialmente de América Latina, en los que estos temas están cobrando protagonismo a pesar de que los procesos socioeconómicos y territoriales presenten diferencias. 


\section{Ampliación del concepto de patrimonio y su importancia para el análisis geográfico}

A finales del siglo pasado, ICOMOS (Consejo Internacional de Monumentos y Sitios) ${ }^{3}$ afirmaba en la Carta Internacional sobre Turismo Cultural que los paisajes, los sitios históricos, los emplazamientos y entornos construidos, así como la biodiversidad, los grupos de objetos diversos, las tradiciones pasadas y presentes, y los conocimientos y experiencias vitales debían ser valorados como patrimonio (ICOMOS, 1999: 1).

Es éste un buen ejemplo de cómo desde la Carta de Venecia (1964), centrada en la noción de monumento histórico, el concepto de patrimonio se ha ido adaptando a los tiempos. Con un origen eminentemente institucional y una plasmación normativa ${ }^{4}$ no exenta de confusión (Silva, 2016: 59), se ha sometido a diversos procesos de ampliación teórica y metodológica, fruto de los cambios sociales y económicos sucedidos en el siglo pasado. Tradicionalmente considerado como el conjunto de bienes que conforman la herencia común de una colectividad, se trata de un "concepto nómada" que hoy se presenta "sin límites y en continua readaptación" (Silva y Fernández, 2017b: 57 y ss.) a la vez que abandera una de las temáticas más multidisciplinares en el ámbito de las ciencias sociales. En las últimas décadas, la preocupación por la protección de lo que se reconocía como "patrimonio", principalmente si se trataba de elementos materiales, como una catedral o un yacimiento arqueológico, se ha convertido en más global cuando el "monumento histórico-artístico" ha sido sustituido por el de "bien cultural", a la vez que se ha dado paso a elementos integrantes de la cultura inmaterial como las tradiciones o los modos de vida (Cañizares, 2009: 93). Su renovación conceptual permite, además, incluir entornos tanto naturales como culturales, aportando un enfoque más integral en el que confluyen razones de carácter ético, científico, social y pedagógico (Ortega, 1998: 33 y ss.), además de incorporar la contemplación del territorio en su extensión y sus paisajes como patrimonio.

Habitualmente dividido en natural y cultural, desde su gestación, asociada al monumento de diversa tipología, el patrimonio natural ha pasado de ser valorado por especies concretas de vegetación o fauna, al reconocimiento global de los espacios, principalmente los protegidos; a la vez, el patrimonio cultural ha evolucionado añadiendo la componente temporal, la naturaleza de los bienes actuales y una gran variedad tipológica, hasta llegar a la consideración del propio territorio como bien cultural. En ambos casos, los avances legislativos ${ }^{5}$ en España han sido fundamentales para entender la situación actual en la que ambos se acercan.

Desde el análisis geográfico en España, Rocío Silva y Víctor Fernández Salinas (2017b: 60 y ss.) realizan una excelente revisión de la evolución del concepto diferenciando tres etapas, respecto a la relación entre el patrimonio y el espacio, que no son lineales y en parte siguen vigentes en un debate continuo. La primera hace referencia al "patrimonio clásico" cuando éste se legitima en sí mismo desvinculado del territorio, desde su origen con la creación del Estado Moderno hasta el

Organización mundial no gubernamental creada en 1965 y asociada a la UNESCO, cuya misión es promover la conservación, protección, uso y desarrollo de los monumentos, conjuntos de edificios y sitios.

Principalmente la Convención sobre la Protección del Patrimonio Mundial Cultural y Natural (Unesco, 1972) y la Convención para la Salvaguarda del Patrimonio Cultural Inmaterial (Unesco, 2003), entre otras.

Principalmente, la Ley 4/1989 de Conservación de Espacios Naturales y de la Flora y Fauna Silvestres, y la Ley 42/2007 del Patrimonio Natural y de la Biodiversidad, junto con la Ley 16/1985 de Patrimonio Histórico Español. 
siglo XIX, al atender a piezas aisladas bien naturales (espacios poco intervenidos), bienes culturales (monumentos y yacimientos arqueológicos) donde cobran protagonismo los centros históricos, ya en el siglo XX. La segunda se centra en "el patrimonio en el territorio" cuando se pasa a tener como referencia éste último y el valor patrimonial se traslada del objeto (bien patrimonial) al sujeto que lo crea (agente de patrimonialización), proceso en el que los ejemplos más antiguos provienen de la protección de la naturaleza (parques), concretándose en el acercamiento entre el patrimonio natural y cultural ${ }^{6}$ (ecomuseos, parques culturales, itinerarios culturales). Y la tercera y última, actualmente vigente, hace referencia al "territorio como patrimonio" en relación con un nuevo paradigma en el que el territorio patrimonial se convierte en un bien cultural complejo donde la faceta territorial implica su descomposición en capas espaciales (estructuras naturales, usos de suelo, poblamiento,...) y temporales (momentos históricos) y cuyo valor recae en los atributos materiales e inmateriales (vectores de patrimonialización) en torno a los que se opera la identificación social y/o institucional, contexto en el que surge el concepto de paisaje patrimonial que abordaremos después. Este reconocimiento del valor patrimonial del territorio, como ha señalado Horacio Capel (2014: 73-74) ha ido aumentando con la atención al patrimonio agrario y rural, y se ha reforzado posteriormente con la defensa del patrimonio minero, marítimo y fluvial.

Para los geógrafos españoles interesados en cuestiones patrimoniales, inmersos en esta última fase, la asimilación de estos cambios ha sido tardía, muy por detrás de otras disciplinas como la historia del arte. Será con la recuperación de la visión cultural en geografía, derivada de Ratzel y Sauer a través del enfoque ofrecido por la "Nueva Geografía Cultural", en el replanteamiento de que no solo hay que tener en cuenta las expresiones materiales de la cultura en un área dada sino también algunos de los rasgos del paisaje para sus habitantes (Fernández, 2006: 228), cuando se comienza a prestar una mayor atención al patrimonio en relación con las singularidades de cada territorio. Primero, en relación con la formulación del patrimonio en el modelo socioeconómico fordista, es decir, atendiendo a su reconocimiento, a las posibles tutelas y su utilización, principalmente recreativa y turística (Fernández, 2005: 5; Feria, 2010: 130). Con el tiempo, se ha convertido en uno de los campos de estudio que más interés despierta desde la aproximación territorial, centrada inicialmente en los centros históricos con gran protagonismo de aspectos arquitectónicos (Troitiño, 1998) y turísticos (Campesino, 1999; Zárate, 2012).

Hoy esta línea se revitaliza a partir de la aparición de documentos como el Convenio Marco sobre el valor del Patrimonio Cultural para la Sociedad del Consejo de Europa, firmado en la ciudad portuguesa de Faro (2005), que expone la necesidad de protección de todas las formas de patrimonio cultural que existen en Europa y avanza hacia una democratización del nuevo patrimonio a través de la participación pública (Mata, 2016: 546). Todo ello se encuentra en conexión con el citado nuevo paradigma que afronta hoy el patrimonio (Silva y Fernández, 2017a, 2017b) en el contexto académico y de la mano de disciplinas como la antropología, según el cual se produce un desplazamiento de la atención prestada a los bienes hacia la que prestan las personas que los crean, los entienden, los disfrutan y también los "recrean", más aún cuando "se puede llamar patrimonio a todo lo que sea activado como tal" (Prats, 2012: 83). En este escenario pierden protagonismo los elementos materiales e inmateriales que lo conforman, para destacar el valor que se les atribuye, bien por las instituciones, bien por la población local, en un proceso de patrimo-

En este proceso han sido fundamentales el Programa MaB de Unesco (1971) y la Red de Reservas de la Biosfera, La Convención para la Protección del Patrimonio Cultural y Natural (1972) y la Lista del Patrimonio Mundial. 
nialización dual. Desde esa concepción, los bienes naturales son culturales dada la existencia de una voluntad de protegerlos (acción cultural), pues, en un proceso de continua transformación, prima la identificación de valores a determinados bienes por la sociedad que en ellos se refleja y se reconoce (Silva, Fernández y Mata, 2018: 19). Puntualmente, la Recomendación sobre Paisajes Urbanos Históricos aprobada por la Unesco (2011) devuelve la atención a las ciudades con un patrimonio relevante, atendiendo al contexto urbano general y su entorno geográfico incluyendo aspectos naturales y culturales.

\section{El patrimonio territorial o el territorio entendido como patrimonio}

José Ortega Valcárcel (1998: 33) aportó, hace algo más de tres décadas, el concepto de patrimonio territorial haciendo referencia al conjunto de recursos culturales y naturales heredados en un espacio geográfico dado, que tiene un elevado grado de aceptación y reconocimiento social, cualificando con ello no solo el objeto edificado sino la "construcción del espacio". Es decir, un entendimiento del territorio como patrimonio, considerando este último como "una unidad en su conjunto" (Calderón y García, 2016: 72).

Identificando la agrupación de recursos naturales y culturales que lo componen, este concepto se acerca también a la noción de desarrollo sostenible que no debe limitarse, lógicamente, a los procesos socioeconómicos (Feria, 2010: 130). Objeto de estudio para numerosos geógrafos españoles se ha relacionado, principalmente, con aspectos como el turismo (Troitiño, 2010; Pillet, 2012; Albarrán, 2016) y, sobre todo, con el desarrollo y la gestión cultural (Feria, 2016; Calderón y García, 2016; Manero, 2017). Sin duda, "la atención otorgada a los diversos componentes que lo integran, de su riqueza intrínseca, de la importancia de las innovaciones metodológicas aplicadas a su estudio e interpretación y de la resonancia de los debates, intereses, contradicciones y conflictos que en torno a él se concitan" (Manero, 2017: 29), lo convierten en un concepto de gran utilidad, aunque difícil de abordar. Precisamente, en este sentido ya se había pronunciado Horacio Capel (1998: 5) al analizar el acercamiento al patrimonio en su vertiente territorial y destacar el esfuerzo por practicar una geografía global, física y humana, muy relacionada con la demanda social de "visiones integradoras", consideración más que vigente en el momento actual, cuando se precisa una geografía que "integre lo ambiental con lo humano" (Hiernaux, 2010: 57), ya que "en lo que respecta a territorio, espacio y relaciones sociedad-naturaleza, la geografía tuvo y tiene aún mucho que decir" (Urquijo y Bocco, 2016: 11), en cualquier contexto territorial.

\section{El Manifiesto por una nueva cultura del territorio (2006) y sus adendas (2009 y 2018)}

En un contexto de urbanización masiva, dificultades de acceso a la vivienda, aumento de la movilidad, burbuja inmobiliaria e incapacidad de la ordenación del territorio en España para su adecuada gestión, surge en 2006 un documento promovido por la Asociación de Geógrafos Españoles (AGE -hoy denominada Asociación Española de Geografía-), con su entonces presidente Rafael Mata, y el Colegio de Geógrafos que fue firmado por numerosos profesionales de esta rama del saber y urbanistas, de gran trascendencia por su contenido. En él se plantea la necesidad de una nueva cultura territorial sustentada en aspectos como la valoración del territorio como "un bien no renovable, esencial y limitado", además de "recurso", a la vez que también es "cultura, historia, memoria colectiva, referente identitario, bien público, espacio de solidaridad y legado" 
(Asociación de Geógrafos Españoles y Colegio de Geógrafos, 2006: 2), en relación con los valores de sostenibilidad ambiental, eficiencia económica y equidad social. Responde a una visión renovada7 que también reconoce la obligación de preservar estos valores, "ecológicos, culturales y patrimoniales que no pueden reducirse al precio del suelo", para las generaciones presentes y futuras, su complejidad y fragilidad, su capacidad como activo económico de primer orden (siempre desde una gestión correcta) y la importancia de que este nuevo enfoque se traslade a la planificación a diferentes escalas (estatal, regional, supramunicipal, local) y a los encargados de tomar las decisiones.

Pocos años después, una vez que España ha ratificado el Convenio Europeo del Paisaje y se ha iniciado la crisis financiera global, la Asociación de Geógrafos Españoles y el Colegio de Geógrafos lanzan, en 2009, su continuación con un documento titulado Territorio, Urbanismo y Crisis enmarcado en una situación económica de recesión donde el buen gobierno del territorio resulta aún más urgente. Apela, de nuevo, a los poderes públicos y a la necesidad de abordar un "cambio en el modelo productivo" y, sobre todo, a aprovechar la crisis como una oportunidad de mejora en barrios y periferias urbanas, en las nuevas áreas de desarrollo urbano, en las zonas rurales y forestales, en la cualificación de las infraestructuras públicas y en las actuaciones en espacios protegidos por su valor patrimonial, natural y cultural en relación con el carácter y la identidad de cada lugar. Su frase final es muy elocuente por su reafirmación en el enfoque patrimonial: "el territorio no puede ser considerado únicamente como recurso explotable o un mero soporte, sino como el marco de vida construido entre todos, mejorando el que recibimos de las generaciones que lo legaron para transmitirlo a las futuras" (Asociación de Geógrafos Españoles y Colegio de Geógrafos, 2009: 2).

En 2018 se ha publicado la última adenda al manifiesto bajo el título En defensa del territorio ante los nuevos retos del cambio global donde se reafirman los valores y principios de los anteriores documentos, a la vez que se exponen los nuevos retos asociados con la gestión del territorio derivados de las grandes transformaciones vinculadas al proceso de cambio global. Se aborda la contribución de la geografía española al análisis de las transformaciones sociales y territoriales ocurridas en los últimos doce años (boom inmobiliario, recesión económica, rescate del sector bancario, etc.), así como la persistencia en las carencias relacionadas con la ordenación territorial y sus políticas en España (a pesar de algunos avances), incapaces de evitar los procesos constantes de degradación. En un contexto, pues, de absoluta necesidad de conocimiento, ordenación y gestión del territorio, este se consolida como "elemento básico de la estructura ambiental de los países, el escenario de desarrollo de las sociedades, el ámbito de redistribución de la riqueza y el bienestar, así como la plasmación visible de los principios que deben regir las sociedades democráticas" (ibidem, 2009: 3). Se hace imprescindible un nuevo “impulso para la ordenación racional del territorio" que debe concretarse en políticas aplicadas en todos los niveles de escala: municipal, metropolitana, regional, estatal y europea, incluyendo la adaptación del espacio geográfico a los efectos del proceso de cambio climático, uno de los retos principales junto con el derecho a la vivienda, la despoblación (para la que se exigen estrategias de desarrollo y medidas específicas en áreas rurales) y la evaluación de la sostenibilidad ambiental y territorial. Se apuesta, además, por las políticas del paisaje y de infraestructura verde del territorio y por la inteligencia territorial

En el cambio de siglo, esta concepción la han reflejado también algunos instrumentos de planificación como el Plan de Ordenación del Territorio de Andalucía (POTA, 2006) en el que se incluye el Sistema de Patrimonio Territorial (Mulero, 2015). 
en relación con la gestión sostenible para el mantenimiento de los valores ambientales y de la calidad de vida. Especialmente destacable es "la activación del patrimonio territorial" en los nuevos territorios del cambio global junto con la equidad, la justicia ambiental, la igualdad de género y la transparencia en procesos administrativos vinculados con la planificación y la gestión.

En conclusión, la consolidación de la "cultura del territorio" se convierte hoy en una "necesidad, alimentada por la calidad de los diagnósticos, el fomento de la educación y la aplicación de los criterios asociados a una visión prospectiva que haga posible la continuidad de los valores patrimoniales, neutralizando las contradicciones y los riesgos" (Manero, 2017: 52).

\section{El protagonismo del territorio y de sus paisajes}

El territorio, entendido desde el enfoque patrimonial como recurso, no exclusivamente como soporte de nuestras actividades, ha cobrado un indudable protagonismo en el cambio de siglo. Su gestión inteligente es fundamental no solo para protegerlo, conservarlo o rentabilizarlo bajo criterios de sostenibilidad, sino para legarlo a la generación futura en la mejor disposición.

\section{Un antes y un después del Convenio Europeo del Paisaje (2000)}

George Bertrand (2010: 6 y ss.) afirmaba que el paisaje había sido un concepto siempre "discutido y discutible" que "no deja de ser móvil y fugaz", actualmente "una noción a la vez tradicional y transgresora" (Silva, 2016: 57), respecto a la que, al menos en Europa, hay un antes y un después de la aprobación del Convenio Europeo del Paisaje (CEP) por el Consejo de Europa en Florencia en 2000, que España ratifica en noviembre de 2007 y entra en vigor el 1 de marzo de 2008.

El "antes" lo conforma una larga tradición que se vincula, inicialmente, con Alexander von Humboldt, y la atención a la naturaleza y al paisaje iniciada a finales de siglo XVIII, "pero sobre todo desde el último cuarto del siglo XIX, con la aplicación explícita del concepto de paisaje a la morfología del territorio" (Martínez de Pisón, 2012: 373). A partir de ese momento diferentes escuelas aportaron su particular punto de vista haciendo de él un elemento explicativo clave en las relaciones hombre-medio, como la escuela rusa (Vassili V. Dukuchaiev,...), la alemana (Siegfried Passarge, Otto Schlütter, Carl Troll...), la francesa (Jean Brunhes, Paul Vidal de la Blache...) y la norteamericana (Carl Sauer), principalmente.

En España, inicialmente, sobresalen las contribuciones de naturalistas, preferentemente geólogos, como José Macpherson, Salvador Calderón y Francisco Quiroga en la segunda mitad del siglo XIX, junto con Lucas Fernández Navarro, Eduardo Hernández Pacheco, Juan Dantín Cereceda o Juan Carandell, ya en el siglo XX, fundamentales en el entendimiento del paisaje natural. Más adelante, Manuel de Terán contribuiría a "la transición, en España, entre una concepción eminentemente naturalista de la geografía a otra de corte decididamente humanista" (Ortega, 2016: 612). Objeto de estudio, sobre todo, para los geógrafos físicos, suscitó gran interés, algo después, la concepción del paisaje como geosistema (Muñoz, 1998, 2004) a través, principalmente, de las aportaciones de George Bertrand (1968). Por su parte, en el ámbito de la geografía humana, los presupuestos fenomenológicos de la geografía humanística se centraron en las aportaciones de Carl Sauer (1925) y sus paisajes culturales, hoy reformuladas por autores como Yi Fu Tuam y Ed- 
ward Soja, y en las aproximaciones culturalistas en las que aparece el "lugar" en relación con la idea humanística del paisaje.

En este contexto, la situación posterior al Convenio tiene mucho que ver con el "redescubrimiento del paisaje" al que asistimos en las últimas décadas, en relación con su "revalorización social, su consideración como recurso económico -nuevo- y la ordenación y gestión de las transformaciones que se producen en el territorio" (Hernández, 2009: 169). El Convenio Europeo del Paisaje, un documento de cierto alcance político, se redacta bajo la preocupación de alcanzar un desarrollo sostenible, reconociendo que el paisaje "desempeña un papel importante de interés general en los campos cultural, ecológico, medioambiental y social", constituye "un recurso favorable para la actividad económica" y cuya "protección, gestión y ordenación puede contribuir a la creación de empleo" (Consejo de Europa, 2000). Más relevante aún, en relación con la valoración de la herencia territorial, es para "la formación de las culturas locales y es un componente fundamental del patrimonio natural y cultural europeo, que contribuye al bienestar de los seres humanos y a la consolidación de la identidad europea".

Su principal aportación es la propia definición según la cual "cualquier parte del territorio tal como la percibe la población, cuyo carácter sea el resultado de la acción y la interacción de factores naturales y/o humanos" conforma un paisaje (CE, 2000) ${ }^{8}$, dejando patente su interrelación con los aspectos culturales y ofreciendo una definición "oficial". Como han reconocido diversos autores (Mata, 2016: 553; Silva, Fernández y Mata, 2018: 18), es innovadora por cuanto permite hablar de los paisajes en plural, tanto de los "excepcionales" como de los "cotidianos o degradados"; pone el énfasis en las percepciones, convirtiéndolo en un concepto intermedio entre el sujeto y su realidad exterior; y finalmente, si todo el territorio tiene interés como paisaje, orienta las intervenciones por acciones de "protección", "gestión" y "ordenación paisajística", cuestiones éstas últimas de gran relevancia (Gómez, 2008; Mata y Tarroja, 2006; Busquets y Cortina, 2009).

Especial atención requiere el carácter como "resultado de la acción y la interacción de factores naturales y humanos", es decir "la huella dactilar de cada territorio" (Silva, 2016: 57) para lo que se han utilizado las metodologías derivadas del Landscape Character Assesment de la agencia escocesa de patrimonio natural, con la subsiguiente diferenciación entre tipos y unidades, así como otras fuentes (literarias, pictóricas...). Aspectos de gran relevancia que deben abordarse, sobre todo la ordenación, a través de un diálogo capaz de armonizar el cambio con la continuidad de los elementos esenciales a partir de tres postulados básicos en los que ha de manifestarse esta capacidad de armonización: la necesidad de conocimiento del medio natural o base física del territorio; la búsqueda de una funcionalidad integrada de todos los elementos territoriales; y la procura de la calidad escénica del conjunto, utilizando determinados hechos y formas para expresar valores culturales, identitarios o simbólicos (Zoido, 2012; Caballero, 2012: 251). Fruto de todo ello es, en la actualidad, la necesidad de integrar el paisaje en las políticas de ordenación territorial y urbanística y en aquellas otras materias como la cultural, medioambiental, agrícola, social y económica, así como en cualesquiera otras políticas que puedan tener un impacto directo o indirecto sobre el paisaje (Cañizares, 2014: 150).

En su redacción colaboró el geógrafo español Florencio Zoido, Catedrático de la Universidad de Sevilla y primer Director del Centro de Estudios Paisaje y Territorio de Andalucía. 


\section{La atención al paisaje por los geógrafos españoles}

Con la aparición del Convenio Europeo del Paisaje y su traslación a la parte política, social y académica, un concepto que tradicionalmente había sido confuso como el paisaje, por su condición polisémica, alcanzaba un rango normativo, al ser acotado y convertido en transdisciplinario (Ojeda, 2013; Silva, 2016); una concepción que suponía "la síntesis de distintas tradiciones" con "consecuencias importantes también para las tareas de identificación y caracterización" que reclamaba, a la vez, "la convergencia de saberes y técnicas de conocimiento paisajístico" (Mata, 2008: 157-158). Su aplicación en España se relaciona, inicialmente, con la elaboración del Atlas de los Paisajes de España coordinado por Rafael Mata y Concepción Sanz (2003) que supuso un excelente ejercicio de tipificación a escala nacional, referencia indiscutible para los atlas de paisajes que se han realizado en algunas regiones españolas, como es el caso de Murcia y de Castilla-La Mancha. Por su parte, los avances legislativos, ante la ausencia de una ley nacional de paisaje, han derivado en leyes regionales aprobadas por diferentes comunidades autónomas como la Valenciana (2004 y 2014), Cataluña (2005), Galicia (2008) o Cantabria (2014), con desigual fortuna en su aplicación.

Desde la investigación geográfica reciente sobresale la atención prestada al paisaje como tema multidisciplinar materializado en diversos proyectos de investigación nacionales y regionales, numerosas aportaciones teóricas (publicaciones, comunicaciones y ponencias en congresos) y algunas aplicadas (planes) de enorme interés. Entre las publicaciones, sobresalen algunas obras conjuntas que son de referencia obligada (Zoido y Venegas, 2002; Ortega, 2004; Mata y Tarroja, 2006; Nogué, 2007; Martínez de Pisón y Ortega; 2008; Gómez y Riesco, 2010; Maderuelo, 2013), a las que unimos el capítulo dedicado al paisaje en la última edición del Atlas del Instituto Geográfico Nacional (Mata, 2018: 479 y ss.), junto con varios monográficos de revistas geográficas españolas ${ }^{9}$. Respecto a los congresos, destacamos la atención prestada al paisaje en el XXI Congreso de la Asociación de Geógrafos Españoles (AGE) celebrado en Ciudad Real en 2009 (Muñoz, 2010; Zoido, 2010) y, sobre todo, su vinculación con las cuestiones patrimoniales en el XXV Congreso AGE en Madrid (2017), donde la ponencia que más comunicaciones recibió llevaba por título “Paisaje, patrimonio e identidad territorial: claves históricas y desafíos actuales" (Cañizares, 2017b). Por su parte, en el campo de la planificación, en el que se ha avanzado bastante, es necesario hacer referencia al Plan Territorial Insular de Menorca y al Plan Especial de Protección de los Valles de Nansa (Cantabria), entre otros varios, cuestión en la que se ha avanzado bastante.

En el ámbito profesional, es imprescindible señalar la creación del Observatori del Paisatge de Catalunya y su labor en la confección de los Catálogos de Paisaje, así como del Centro de Estudios Territorio y Paisaje de Andalucía; en ambos, Joan Nogué y Florencio Zoido, respectivamente, junto con un nutrido grupo de geógrafos y de otros profesionales han sentado las bases del trabajo aplicado en esta materia. Finalmente, debe añadirse que el interés actual del paisaje para los geógrafos españoles se ha materializado en 2013 con la creación del Grupo de Trabajo de Paisaje dentro de la Asociación de Geógrafos Españoles, presidido por Gabriel Alomar, que desarrolla anualmente Jornadas de Trabajo bastante innovadoras ${ }^{10}$.

\footnotetext{
Ería. Revista Cuatrimestral del Geografía, 73-74 (2007); Cuadernos Geográficos, 43 (2008-2) y 51 (2012); Estudios Geográficos, 269 (2010); Polígonos. Revista de Geografía, 26 (2014) y Ciudad y Territorio/Estudios Territoriales, 184 (2015).

10 Hasta ahora se han celebrado en Menorca (2017) bajo el epígrafe Paisaje: ética y estética, Burgos (2018) 10 años del Convenio Europeo del Paisaje y las próximas serán en la Serranía de Ronda (2019) Paisaje e Identidad.
} 
Este breve recorrido nos permite comprobar cómo el paisaje, siguiendo a Florencio Zoido (2012), se ha convertido en un concepto útil para relacionar estética, ética y política, combinación de pasado, presente y futuro, un recurso intelectual que antecede a la propia ordenación del territorio. Además, la incorporación de aspectos identitarios lo han acercado al patrimonio, como analizaremos a continuación. A partir de la importancia concedida al hombre y a la percepción, se suman diferentes las miradas aportadas por la literatura (Pillet, 2014, 2015), la pintura (Fernández, 2015), el cine o la fotografía, principalmente, que entroncan con la tradición paisajística de carácter cultural, y se relaciona el paisaje con actividades económicas como el turismo (Espejo, 2011). No menos importante es su utilidad social (Mata, 2014: 11) pues el Convenio expone que el paisaje es, ante todo, "un elemento importante de la calidad de vida de las personas en todas partes, en los medios rurales y urbanos, en las zonas degradadas y en las de gran calidad, en los espacios de reconocida belleza excepcional y en los más cotidianos" (Consejo de Europa, 2000). Hoy actúa como catalizador, "elemento vertebrador de la creciente conflictividad de carácter territorial y ambiental palpable en nuestra sociedad" (Nogué, 2010: 123).

Sin duda, la renovación del concepto de paisaje y el creciente interés por su conocimiento, salvaguarda y gestión hay que incardinarlos en un contexto global de graves problemas ambientales y de una demanda social en aumento de paisajes de calidad, como entornos de vida cotidiana y como recursos para el desarrollo territorial (Sabaté, 2004, 2011). Esas circunstancias explican que el paisaje -todos los paisajes y no solo los más valiosos y apreciados-, se haya incorporado al debate ciudadano y a la agenda política europea en la doble condición de espacios vividos y de expresión de la identidad de los lugares (Mata, 2018: 480).

\section{Paisaje e identidad territorial}

Desde la perspectiva geográfica, la identidad es una manifestación de referencia territorial que alimenta el anclaje al territorio remite a las especificidades de cada espacio geográfico, siendo central la incidencia que tiene en los procesos internos y externos de construcción de los lugares. Además de su papel en la explicitación que se hace de esos espacios, definiendo los componentes que los caracterizan, diferencian y/o asemejan a otros territorios y otras sociedades, identidad y territorio aportan naturaleza, simbólica y material, y contribuyen a la relación espacial y temporal de la sociedad (Benedetto, 2010). En este sentido se encuentra unida al concepto de "lugar", incluso actualmente al "espíritu del lugar", analizado en la geografía española por la vertiente humanística, pues "el paisaje no existe más que en relación al ser humano, en la medida que éste lo percibe y se apropia de él [...], está vinculado a un lugar y personalizado por ese lugar" (Nogué, 2010: 124). En general, el concepto de identidad plantea el sentimiento de pertenencia a una comunidad con rasgos propios, según los antropólogos, y sitúa al hombre (sociedad) en el centro del discurso. En su traslación a los estudios geográficos y por tanto en su vinculación con la dimensión espacial, se relaciona con el territorio y sus paisajes desde la visión patrimonial, resaltando que éstos tienen "un papel relevante en la formación y consolidación de identidades territoriales" (Nogué, 2010: 123), no solo en la actualidad sino en otros períodos históricos.

El mencionado Manifiesto por una nueva cultura del territorio (Asociación de Geógrafos Españoles y Colegio de Geógrafos, 2006), desde su concepción patrimonial, señala que "la sociedad encuentra en él soporte o sustento material a sus necesidades", a la vez que es "referente de su identidad y cultura". Destaca cómo las características naturales y la pervivencia de trazos del pa- 
sado (culturales) de cada territorio le ofrecen "singularidad y valores de diversidad"; algo, como es sabido, muy importante en un mundo global que tiende a la uniformización y que se debe preservar para transmitirlo a la generación futura en la mejor disposición posible, es decir, bajo criterios de sostenibilidad. Por su parte, el Convenio europeo del paisaje (Consejo de Europa, 2000) también resalta que el paisaje "contribuye al bienestar de los seres humanos y a la consolidación de la identidad europea". Una identidad que se salvaguarda como uno de los elementos más valiosos de la cultura en nuestro entorno inmediato y que, en la propia elaboración del texto, se trató con especial atención para evitar la conflictividad social (nacionalismos...), destacando las escalas locales como las más adecuadas para la asunción de los valores de un territorio.

Si el paisaje "se entiende estrechamente ligado a quienes lo habitan, a su modo de ser y de actuar, a sus formas de pensar y de sentir, a su historia", es obvia su contribución a "la identidad colectiva" (Ortega, 2009: 27). Hoy se le reconoce su implicación en "la formación de las culturas locales" como "componente fundamental del patrimonio natural y cultural" y, por tanto, también en "la consolidación de la identidad" (Mata, 2014: 11). En realidad, todos los paisajes son rostros de formas territoriales, expresiones de estructuras espaciales, geográficas, naturales, históricas, ecológicas, económicas, sociales y culturales que muestran la configuración de un lugar y aportan el peso de la influencia de una cultura en un espacio; son también imágenes de sí mismos e incluso expresiones morales de la relación de unos hombres con sus lugares; como consecuencia, los paisajes revelan "la identidad de quienes los habitan y en su configuración encuentran tal identidad esos hombres" (Martínez de Pisón, 2012: 374).

El Convenio de Faro (2005), antes citado, relaciona también el patrimonio con su contribución a la base común de la memoria, al entendimiento mutuo, la identidad, el sentimiento de pertenencia y la creatividad de la sociedad. Más recientemente, el dictamen del Comité Europeo de las Regiones Hacia un enfoque integrado del Patrimonio Cultural europeo (2015) destaca que el patrimonio cultural constituye una piedra angular en la identidad local, regional, nacional y europea. Su conservación y protección, así como el refuerzo de la identidad social a nivel local y regional, son elementos fundamentales para la sostenibilidad, que garantizarán la conservación de los valores europeos para las generaciones venideras y la continuidad de las tradiciones y los conocimientos; contexto en el que los valores culturales, es decir, la creación artística, literaria, audiovisual y arquitectónica; el trabajo creativo; la cultura contemporánea; el artesanado; el folclore; el patrimonio arqueológico, histórico, religioso y etnográfico; los dialectos; la música; los alimentos y la gastronomía; las particularidades paisajísticas y naturales; la experiencia y los saberes tradicionales; el saber hacer; las tradiciones vivas, etc., están estrechamente ligados a la identidad, arraigada en el patrimonio material, inmaterial y natural de las comunidades. El desarrollo de la cultura a nivel local fortalece la identidad de una ciudad o región, así como su carácter propio; y la combinación, desde el respeto mutuo, de las diferentes identidades ayuda a construir el patrimonio cultural común.

En los últimos años, el discurso identitario "ejerce un rol social y cultural destacado" (Nogué, 2010: 125), incluso, en ocasiones, el propio patrimonio sirve para sacralizarlo (Prats, 2006: 72; Silva y Fernández, 2017b: 57), pero también se relaciona, a veces, no tanto con las potencialidades de un determinado territorio, imprescindibles para la puesta en marcha de estrategias de desarrollo, sino con la degradación e incluso pérdida de los "anclajes espaciales" que vinculan emocionalmente a las personas con su lugar de nacimiento o residencia (Cortés, 2015: 136), lo 
cual ha redundado, a menudo, en movimientos sociales que denuncian las alteraciones de las que se derivan procesos de pérdida de calidad e identidad de los paisajes (Hernández, 2009: 174), marco en el que la labor del geógrafo es, además, especialmente válida cuando los procesos de degradación y transformaciones son irreversibles.

\section{Los Paisajes Culturales en la confluencia entre patrimonio y paisaje}

Eduardo Martínez de Pisón (2012: 373), afirmaba que "para el geógrafo actual, el paisaje es el lugar y su imagen: la configuración la adquieren los hechos geográficos más sus percepciones y representaciones culturales"; es decir, la "cultura", entendida como herencia transmitida, es indisociable de los paisajes habitados por el hombre. Desde un renovado entendimiento del paisaje como carácter del territorio percibido socialmente, modelado a lo largo del tiempo en un proceso permanente de recomposición y rehabilitación de ambientes heredados (Mata, 2014: 19), abordamos a continuación los paisajes culturales como concepto que presenta una gran utilidad en el análisis conjunto del patrimonio y el territorio.

\section{Paisajes y paisajes culturales}

Para el geógrafo brasileño Milton Santos, el paisaje existía "a través de sus formas, creadas en momentos históricos diferentes, pudiendo coexistir en el momento actual" (Santos, 1996: 84); es decir, que hablamos de algo dinámico y evolutivo donde podemos descubrir el paso del hombre en el tiempo, lo que convierte a los paisajes en "totalizadores territoriales e históricos" (Silva, Fernández y Mata, 2018: 23).

La dimensión cultural en relación con los paisajes se ha desarrollado tarde en la geografía española. Si bien entronca, principalmente, con la tradición geográfica de las escuelas francesa ("genero de vida" de Vidal de la Blache) y la norteamericana ("paisaje cultural" de Sauer) recuperadas por el enfoque humanista y culturalista, no ha sido hasta las últimas décadas cuando el geógrafo que se ha acercado al paisaje lo ha hecho destacando su vertiente cultural. Precedentes significativos son los trabajos de Nicolás Ortega Cantero, quien ha analizado (2016: 600 y 613), entre otras cuestiones, la adaptación de la interpretación del paisaje contemporánea fundada por Humboldt desde los naturalistas, centrados en el paisaje natural y en la geografía física. Más adelante, destaca Manuel de Terán en el marco de la geografía académica y en la unión de elementos naturales y culturales, hasta llegar a Eduardo Martínez de Pisón (1997; 2007: 330), lo que hoy llamaríamos un geógrafo integral, cuando a finales del siglo XX afirmó que el paisaje es patrimonio cultural y, más adelante, que todos los paisajes son por definición culturales, pues son "acumuladores de herencias que fijan el proceso que los forma: son productos y muestras de su historia".

En esa confluencia entre patrimonio y territorio, y siempre en un contexto multidisciplinar, el interés en la geografía española se ha derivado, de su aplicación a los espacios urbanos y a los espacios productivos, preferentemente, siendo destacable la valoración del territorio como recurso patrimonial en relación con el desarrollo (Caravaca y Fernández, 2005: 23; Sabaté Bel, 2004; Feria, 2010, 2016;), con los paisajes agrarios (Cabero, 2002, Silva, 2009) o en su aplicación al turismo (Troitiño, 2010). 
Los procesos recientes hacen del paisaje "un sistema funcional en permanente movimiento, en el que circulan flujos de materiales, de energía, de organismos vivos -incluyendo a los seres humanos- y de información" (Mata, 2008: 158). Y, en este contexto, ya hemos analizado su reconocimiento como "cultura" y, precisamente por ello, "algo vivo, dinámico y en continua transformación, en continua mutación" (Nogué, 2010: 128). Cuestiones a las que se unen los cambios analizados en el concepto de patrimonio y, específicamente, la asunción del territorio como patrimonio (territorios patrimoniales/patrimonio territorial), que reflejamos en el esquema siguiente (Figura $N^{\circ} 1$ ) exponiendo las claves teóricas que explican el análisis geográfico de los paisajes culturales. Teniendo en cuenta estas premisas, en el encuentro de los conceptos de patrimonio y paisaje (Gómez, 2013) y, por tanto, en la confluencia entre ambos paradigmas (Fernández y Silva, 2015), radica este enfoque que pone la atención sobre los aspectos culturales sin obviar los propiamente naturales. En esa aproximación, el patrimonio incluye al paisaje y, no sin paradoja, la noción de paisaje se amplía superando su acepción elitista y patrimonialista inicial (Silva, Fernández y Mata, 2018: 24).

Especial relevancia adquieren, pues, los procesos de patrimonialización, consecuencia lógica del descubrimiento de sus valores para las poblaciones que los habitan y viven de diversas formas y, en ocasiones, incluso para toda la humanidad (Sanz, 2012: 700). La conversión del paisaje en "patrimonial" se opera mediante procesos de apropiación social y de asignación de valores que pueden actuar, como hemos señalado, de abajo arriba, cuando es la sociedad civil la que los promueve, y de arriba abajo, cuando la valoración patrimonial proviene de la presencia de remiendos normativos institucionales o de la existencia de estudios académicos (Ojeda, 2013; Silva, 2016; Silva y Fernández, 2017a, 2017b; Silva, Fernández y Mata, 2018: 26).

Figura No 1

Claves teóricas para el análisis geográfico de los Paisajes Culturales

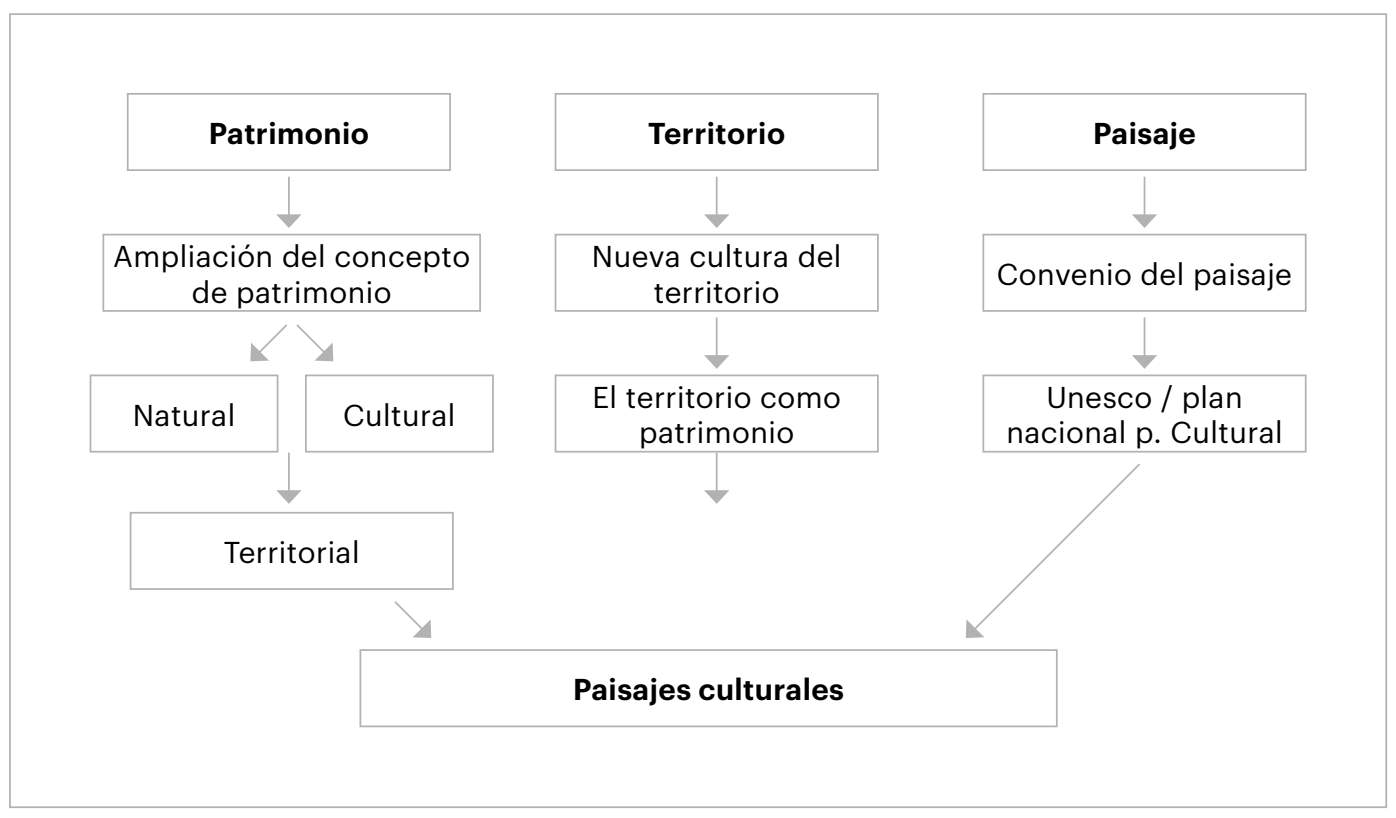

Fuente: Elaboración propia. 
El tratamiento patrimonial de los paisajes ha contribuido a la creación de términos de segunda generación (Silva, 2016: 56), adjetivos que se añaden al paisaje como protegidos, de interés cultural, de excepcional valor patrimonial, sobresalientes, singulares, y sobre todo, culturales y patrimoniales. Nos centraremos brevemente en estos dos últimos: el primero de ellos, actualmente el más sólido, es el de paisaje cultural que procede del marco institucional, pues es la Unesco quien los define, en 1992, como "obras conjuntas del hombre y la naturaleza", lugares que combinan el trabajo de la naturaleza y el ser humano, y son ilustrativos de la evolución de la sociedad humana y del uso del espacio a través del tiempo, bajo la influencia de limitaciones físicas y/o oportunidades presentadas por el medio natural y las sucesivas fuerzas sociales, económicas y culturales (Fernández y Silva, 2015: 262). Una categoría con la que, a escala global, se iniciaba la protección legal internacional de los paisajes culturales, catalogando como tales aquellos que poseían "un excepcional valor universal" y cumplieran uno o varios de los criterios sometidos a revisión periódica (Cañizares, 2014: 154 y ss.). Transcurridos unos años es evidente que esta labor institucional, con sus luces y sus sombras, que las tiene sobre todo en aspectos metodológicos (Fernández y Silva, 2015), ha contribuido al reconocimiento y valoración de los paisajes más allá de criterios naturales y estéticos exclusivamente. Hoy la catalogación de un paisaje como "cultural" por la Unesco, como ocurre con los españoles de Aranjuez, Pirineos-Monte Perdido (transfronterizo compartido con Francia), de la Sierra de la Tramontana mallorquina (Figura No 2), y de Risco Caido y Montañas Sagradas de Gran Canaria", no solo permite abordar el reconocimiento de su valor universal sino que le imprime una "imagen de marca" muy valiosa en el contexto del desarrollo territorial".

Figura $\mathrm{N}^{\circ} 2$

Paisaje Cultural de la Sierra de la Tramontana (Mallorca, España)

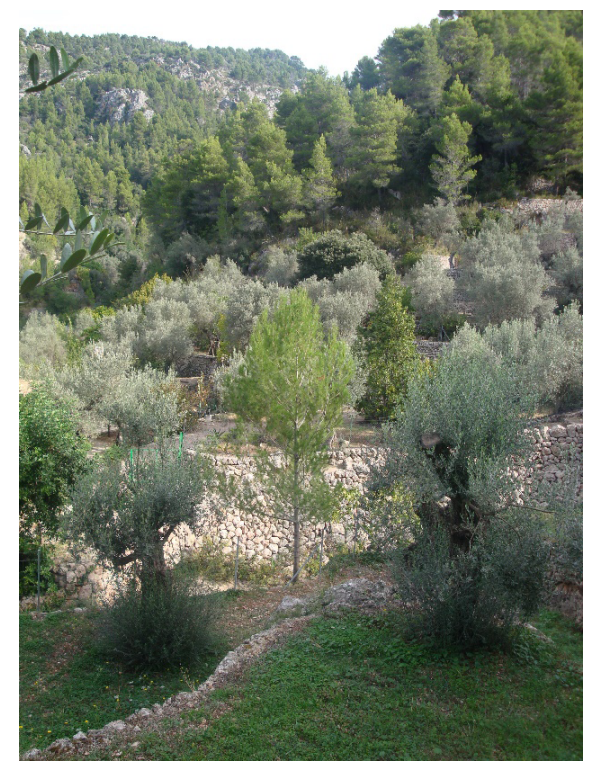

Fuente: Elaboración propia (2015).

Su traslación al ámbito jurídico español la han realizado varias comunidades autónomas: Cantabria (Ley 11/1998 de 13 de octubre de Patrimonio Cultural), La Rioja (Ley 7/2004 de Patrimonio Cultural, Histórico y Artístico), Navarra (Ley Foral 14/2005 de Patrimonio Cultural), Murcia (Ley 4/2007 de Patrimonio Cultural) y Madrid (Ley 3/2013 de 17 de junio de Patrimonio Histórico), aspecto relevante a efectos de protección. 
En el contexto de la planificación, el Instituto del Patrimonio Cultural de España cuenta desde 2011 con el Plan de Paisaje Cultural, que asume el bien "paisaje cultural" como objeto de la política de patrimonio y, por tanto, incorpora valores y gestión patrimonial a la escala del territorio, propiciando así, desde la perspectiva cultural, la coordinación y cooperación con otras administraciones (autonómicas y locales), con otras políticas sectoriales de alta incidencia en el estado y la dinámica del paisaje. Definido como el "resultado de la interacción en el tiempo de las personas y el medio natural, cuya expresión es un territorio percibido y valorado por sus cualidades culturales, producto de un proceso y soporte de la identidad de una comunidad" (IPC, 2015: 25), aporta un enfoque novedoso por cuanto no se restringe a los paisajes de excepcional valor, siguiendo el Convenio Europeo del Paisaje (Mata, 2016: 553). Algunos geógrafos, en especial Rafael Mata, han participado en su elaboración y en la publicación de la obra 100 Paisajes Culturales de España (Cruz, 2015) en la que se establece una diferenciación funcional en cuatro grandes grupos: paisajes agrarios, ganaderos y forestales; paisajes industriales, infraestructuras y actividades comerciales; paisajes urbanos, históricos y defensivos; y paisajes simbólicos.

Esta interacción entre paisaje y patrimonio ha sido objeto de atención por parte de los geógrafos españoles (Silva, 2016: 60) a través de diversos estudios en relación con ciudades monumentales (Mínguez, 2007; Zárate, 2011, 2012) o espacios naturales protegidos (Mulero, 2013), junto con los agrarios (Silva, 2009; Mata, 2015), principalmente, así como diversos proyectos de investigación en el marco del Programa Nacional de Investigación de los cuales y de las publicaciones resultantes se han derivado algunos de los avances más recientes en esta temática ${ }^{12}$. En este sentido, sobresale la obra titulada Paisajes Patrimoniales de España, a la que antes hemos aludido (Molinero y Tort, 2018), ya que aporta un recorrido paisajístico exhaustivo al trabajar 70 unidades a partir de la integración de dominantes morfológicas o territoriales que definen el carácter (natural, rural, urbano), funcionales (agrario, minero, industrial) y temporales referidas al período de tiempo en el que se desarrollan sus trazas más visibles (medievales, renacentistas, contemporáneos...) o bien se relacionan con atributos perceptivos (por ejemplo, jacobeos) como resultado de la colaboración de más de 70 investigadores de diferentes universidades ${ }^{13}$. Su principal aportación teórica es el reconocimiento de que el propio término de paisaje cultural es una redundancia, dado que los paisajes son construcciones mentales, proponiendo el concepto de paisajes patrimoniales, entendidos como aquellos de especial interés cultural, que por sus altos valores merezcan ser objeto de reconocimiento y tutela (Mata, de Meer y de la Puente, 2012; Silva, Fernández y Mata, 2018: 21). Con un cierto recorrido en la geografía española, supone una apuesta muy destacada por conceptualizar este ámbito temático tan atractivo.

Especial atención requieren los vectores patrimoniales al identificar aquello que hace valioso a cada uno de los paisajes y no solo diferente, que es lo que identifica el carácter. Es decir, realida-

Destacamos el proyecto Paisajes Patrimoniales de España (2012-2015) que agrupó varios subproyectos coordinados: La España Interior Septentrional y Occidental (Universidad de Valladolid), La España Interior Centro-Meridional (Universidad Autónoma de Madrid), La España Insular Canaria (Universidad de La Laguna), La España Atlántica y Navarra (Universidad del País Vasco), La España Mediterránea y el Valle del Ebro (Universitat Rovira i Virgili) y La España Meridional Andaluza (Universidad de Sevilla)

13 Sobresalen también otros proyectos como Cultura y patrimonio como recursos territoriales. Estrategias de desarrollo sostenible e impactos espaciales 2013-2015 (Universidad de Valladolid) y Paisajes Culturales de la Lista del Patrimonio Mundial: claves para la identificación y criterios para la gestión de paisajes urbanos históricos y reales sitios 2015-2018 (Universidad Autónoma de Madrid) al que se vinculan tres más: Regadíos tradicionales históricos (Universidad de Barcelona); Dehesas, montados ibéricos y olivares mediterráneos (Universidad de Sevilla), y Paisajes agroganaderos, mineros e industriales de la España atlántica (Universidad del País Vasco), junto a los que se añadió, Paisajes de los viñedos y vinos con valor patrimonial (Universidad de Valladolid) 
des y procesos a partir de los que se construye el reconocimiento patrimonial (Fernández y Silva, 2015: 258), que poseen un valor identitario atribuido a la población local o en relación con un reconocimiento histórico, artístico, simbólico o similar desde las instituciones. El objetivo final es saber qué es patrimonial en un paisaje y dónde se localiza aquello que le confiere ese valor para saber qué proteger, ordenar y gestionar (Silva, 2016: 60). Por su parte, la matriz vectorial sería el argumento común y genérico, es decir la tipología, de la que proceden los vectores (Fernández y Silva, 2016: 181). En este contexto, como hemos avanzado, la patrimonialización del paisaje es clave, pues implica la asociación de valores a determinados bienes, bien por el grupo humano que proyecta en ellos su identidad, bien por las instituciones que le atribuyen cualidades artísticas, simbólicas, conmemorativas, etc. Su aplicación al territorio español permite relacionarlo con el medio natural, es decir parques nacionales, naturales, rurales y/o regionales (según autonomías), un total de 311, y con los 57 paisajes protegidos, a los que se unen las Reservas de la Biosfera y los ámbitos incluidos en la Red Natura 2000, todos susceptibles de constituir paisajes patrimoniales. Por su parte, según la legislación de patrimonio, se podrían incluir también las figuras de conjuntos históricos, sitios históricos, zonas arqueológicas y jardines históricos, casi 2.300 bienes en España (Silva, Fernández y Mata, 2018: 31).

\section{Conclusiones}

La labor del geógrafo, en un marco pluridisciplinar y en relación con la temática que une patrimonio y territorio se manifiesta de gran utilidad en el momento actual. Más aún en un contexto de intensas transformaciones socioeconómicas, territoriales, culturales y tecnológicas que se han ido solapando en las últimas décadas. Partiendo de una reflexión teórica sobre los procesos y retos que han consolidado esta temática, durante las últimas décadas en España, se ha realizado un análisis de cómo han sido abordados los conceptos de patrimonio, patrimonio territorial, paisaje y paisajes culturales por los geógrafos españoles mediante una revisión integrada por las principales aportaciones de expertos (Eduardo Martínez de Pisón, Horacio Capel Saez, Florencio Zoido Naranjo, Miguel Ángel Troitiño Vinuesa, Rafael Mata Olmo, Joan Nogué i Font, Fernando Molinero Hernando, Víctor Fernández Salinas, Rocío Silva Pérez...). Si bien los debates se mantienen abiertos permanentemente, quizás debido a la dificultad de asentar conceptos que continuamente se están ampliando y reinventando (patrimonio, territorio, paisaje), parece obvio que, sobre todo, es en la gestión y tutela del territorio donde mejores aportaciones se pueden realizar, ante la destrucción del propio patrimonio y de los paisajes culturales. Aspecto, este, en el que tienen gran relevancia las aportaciones institucionales a diferentes escalas, tales como los diferentes convenios y acuerdos de Unesco y la Lista del Patrimonio Mundial, en el ámbito internacional; el Convenio Europeo del Paisaje aprobado por el Consejo de Europa, en la escala supraestatal; o el Plan Nacional de Paisaje Cultural, en España. Junto con ello, la consolidación de conceptos como el de paisaje cultural es considerada de especial interés no solo en el contexto científico-académico, sino sobre todo en el político por su relación con las posibles herramientas de planificación y ordenación territorial.

Los retos de futuro son múltiples: en primer lugar, seguir ofreciendo una visión integral que permita conjugar geografía física y humana en su vertiente más aplicada; en segundo lugar, la necesidad de hacer inteligible la relación entre patrimonio y paisaje, no tanto desde el punto de vista teórico, que también, sino sobre todo para facilitar las acciones de inteligencia territorial; 
en tercer lugar, proporcionar herramientas fáciles y útiles para los políticos en la toma de decisiones y para los agentes que se encargan de esas labores, de manera que se pueda contribuir a la operatividad y eficacia en las decisiones que tienen una dimensión territorial siempre bajo criterios de sostenibilidad; $y$, finalmente, analizar y denunciar los riesgos que la patrimonialización del territorio conlleva, en concreto relacionados con las estrategias de desarrollo territorial que encuentran en el turismo, no siempre bien planificado, la panacea para salvar algunos territorios del declive. En definitiva, aprovechar la valía de la disciplina geográfica para proteger, ordenar y gestionar adecuadamente los paisajes, que en sí mismos son culturales.

\section{Referencias bibliográficas}

ALBARRÁN, J.D. El concepto de Patrimonio Territorial: problemáticas de gestión y planificación turística. En: BLÁZQUEZ, M. et al. (eds.). Turismo y crisis, turismo colaborativo y ecoturismo. Palma de Mallorca: AGE y SHNB, 2016, p. 67-78.

ASOCIACIÓN DE GEÓGRAFOS ESPAÑOLES y COLEGIO DE GEÓGRAFOS. Por una nueva cultura del Territorio, 2006. https://www.age-geografia.es/site/wp-content/uploads/2018/10/Manifiesto-por-una-nueva-cultura-del-territorio-2006.pdf. (Consultado 27-06-2019).

ASOCIACIÓN DE GEÓGRAFOS ESPAÑOLES y COLEGIO DE GEÓGRAFOS. Territorio, Urbanismo y Crisis. 2009. https://www.age-geografia.es/site/wp-content/uploads/2018/06/ Adenda-2009_MANIFIESTO_NuevaCulturadelTerritorio.pdf (Consultado 27-06-2019).

ASOCIACIÓN DE GEÓGRAFOS ESPAÑOLES y COLEGIO DE GEÓGRAFOS. Adenda. En defensa del territorio ante los nuevos retos del cambio global. 2018. https://www.age-geografia.es/site/adenda-2018-al-manifiesto-de-la-nueva-cultura-del-territorio/ (Consultado 27-06-2019).

BENEDETTO, M. A. Identidad y territorio: aportes para el desarrollo local en áreas rurales de la provincia de Mendoza. Estrategias con identidad territorial. Breves Contribuciones del IEG-Instituto de Estudios Geográficos “Dr. Guillermo Rohmeder", 2010, vol. 21, n, 21.

BERTRAND, G. Paysage et géographie physique globale. Esquisse méthodologique. Revue Géographique des Pyrenées et du Sud-Ouest, 1968, №39, p. 249-272.

BERTRAND, G. Itinerario en torno al paisaje: una epistemología de terreno para tiempos de crisis. Ería. Revista de Geografía, 2010, № 81, p. 5-38.

BOLÓS i CAPDEVILLA, M. de. Manual de ciencia del paisaje. Barcelona: Masson, 1992.

BUSQUETS, J. y CORTINA (coords.). Gestión del paisaje. Manual de protección, gestión y ordenación del paisaje. Barcelona: Ariel, 2009.

CABALLERO, J.V. Los valores paisajísticos. Elementos para la articulación entre teoría e interpretación del paisaje. Cuadernos Geográficos, 2012, No 51, p. 245-269. 
CABERO, V. Paisajes rurales y culturales: conservación, educación y desarrollo. Medio ambiente: calidad ambiental, 2002, № 32, p. 213-240.

CALDERÓN, B. y GARCÍA, J.L. Patrimonio y Territorio en España, fundamentos y estrategias para la gestión de la cultura territorial. En: MANERO, F. y GARCÍA CUESTA, J.L. (coords.). Patrimonio cultural y desarrollo territorial. Pamplona: Thomson Reuters/Aranzadi, 2016, p. 51-105.

CAMPESINO, A.J. (dir.). Comercio, turismo y cambios funcionales en las ciudades españolas Patrimonio de la Humanidad. Cáceres: Cámara Oficial de Comercio e Industria de Cáceres y Caja de Extremadura, 1999.

CAMPESINO, A.J.; DARÍAS, A. y BUCHO, D. Ciudades abaluartadas de la raya ibérica: de frontera a paisaje cultural de la humanidad. PH Boletín del Instituto Andaluz de Patrimonio Histórico, 2006, No 60, p. $74-83$.

CAÑIZARES, M.C. Cultura y patrimonio en clave territorial: las aportaciones del geógrafo. En: FERIA, J.M.; GARCÍA, A. y OJEDA, J.F. (coords.). Territorios, sociedades y políticas. Sevilla: Universidad Pablo de Olavide y AGE, 2009, p. 93-105.

CAÑIZARES, M.C. Protección y defensa del patrimonio minero en España. Scripta Nova. Revista Electrónica de Geografía y Ciencias Sociales, Vol. 15, № 361, 2010. [http://www.ub.edu/geocrit/sn/ sn-361.htm]. (Consultado 27-06-2019).

CAÑIZARES, M.C. Paisajes culturales, ordenación del territorio y reflexiones desde la Geografía en España. Polígonos. Revista de Geografía, 2014, № 26, p. 147-180.

CAÑIZARES, M.C. Paisaje, patrimonio e identidad territorial: claves históricas y desafíos actuales. En ALLENDE, F.; TORRECILLA, R.; FERNÁNDEZ-MAYORALES, G.; GÓMEZ, G.; LÓPEZ, N.; PALACIOS, A.; ROJO, F. y VIDAL, M.J. (eds.). Naturaleza, territorio y ciudad en un mundo global. Madrid: AGE y Universidad Autónoma de Madrid, 2017b, p. 1725-1744.

CAPEL, H. Una Geografía para el siglo XXI. Scripta Nova. Revista Electrónica de Geografía y Ciencias Sociales, No 19, 1998. [http://www.ub.edu/geocrit/sn-19.htm]. (Consultado 27-06-2019).

CAPEL, H. El patrimonio: la construcción del pasado y del futuro. Barcelona: Ediciones del Serbal, 2014.

CARAVACA, I. y FERNÁNDEZ, V. Patrimonio y Desarrollo Territorial. En: CARAVACA, I. y FERNÁNDEZ SALINAS, V. (coords). Jornadas de Patrimonio y Territorio. Sevilla: Consejería de Cultura de la Junta de Andalucía, 2005, p. 5-18.

CONSEJO DE EUROPA (2000). Convenio Europeo del Paisaje, Estrasburgo. [https://www.mapa. gob.es/es/desarrollo-rural/planes-y-estrategias/desarrollo-territorial/ convenio.aspx]. (Consultado 27-06-2019). 
CONSEJO DE EUROPA. Convenio Marco sobre el Valor del Patrimonio Cultural para la Sociedad, Faro, 27 de octubre de 2005. [https://rm.coe.int/16806a18d3]. (Consultado 27-06-2019).

CLAVAL, P. Champ et perspectives de la géographie culturelle dix ans après. Géographie et Cultures, 2001, No 40 , p. 5-28.

COPETA, C. y LOIS, R. C. (coords.) Geografía, paisaje e identidad. Madrid: Biblioteca Nueva, 2009.

CORTES, J. Identidad territorial y paisaje. Evolución morfológica de los núcleos de Castilla y León. Observatorio Medioambiental, 2015, № 18, p. 131-147.

CRUZ, L. (coord.). 100 Paisajes Culturales en España. Madrid: Ministerio de Educación, Cultura y Deporte, 2015.

ESPEJO, C. El paisaje como recurso turístico. En: SIMANCAS, M.R. y CORTINA, A. (coords.): Retos y perspectivas de la gestión del paisaje de Canarias. Las Palmas: Gobierno de Canarias y Universidad Internacional Menéndez Pelayo, 2011, p. 439-461.

FERIA, J.M. Patrimonio territorial y desarrollo sostenible: un estudio comparativo en Iberoamérica y España. Estudios Geográficos, 2010, № 258, p. 129-159.

FERIA, J.M. Patrimonio territorial y desarrollo sostenible. En: MANERO, F. y GARCÍA CUESTA, J.L. (coords.). Patrimonio cultural y desarrollo territorial. Pamplona: Thomson Reuters/Aranzadi, 2016, p. 25-50.

FERNÁNDEZ, F. Geografía Cultural. En HIERNAUX, D. y LINDÓN, A. (dirs.). Tratado de Geografía Humana. Barcelona: Anthropos, 2006, p. 220-253.

FERNÁNDEZ, J. El paisaje agrario en Castilla y León: los secanos cerealistas según los pintores de la segunda mitad del siglo XX. Cuadernos Geográficos, 2015, № 54/1, p. 113-134.

FERNÁNDEZ, V. Patrimonio y Desarrollo: ¿Realidad o deseo?. En: CARAVACA, I. y FERNÁNDEZ, V. (coords). Jornadas de Patrimonio y Territorio. Sevilla: Edit. Consejería de Cultura de la Junta de Andalucía, 2005, p. 29-62.

FERNÁNDEZ, V. y SILVA, R. Criterios para la identificación y selección de paisajes españoles susceptibles de ser incluidos en la Lista del Patrimonio Mundial de Unesco. Boletín de la Asociación de Geógrafos Españoles, 2015, No 68, p. 253-278.

FERNÁNDEZ, V. y SILVA, R. Deconstruyendo los paisajes culturales de la Lista del Patrimonio Mundial de la Unesco. Cuadernos Geográficos, 2016, No 55(1), p. 176-197.

GÓMEZ, J. La mirada del geógrafo sobre el paisaje: del conocimiento a la gestión". En: MADERUELO, J. (coord.): Paisaje y territorio. Madrid: Abada, 2008, p. 11-56. 
GÓMEZ, J. Del patrimonio paisaje a los paisajes patrimonio. Documents d'Anàlisi Geogràfica, 2013, No $59 / 1$, p. 2-20.

GÓMEZ, J. y RIESCO, P. Marco Conceptual y metodológico para los paisajes españoles: aplicación a tres escalas espaciales. Sevilla: Consejería de Obras Públicas y Vivienda y Centro de Estudios Paisaje y Territorio, 2010.

HERNÁNDEZ, M. El paisaje como seña de identidad territorial. Boletín de la Asociación de Geógrafos Españoles, 2009, № 49, p. 69-183.

HIERNAUX, D. La geografía hoy: giros, fragmentos y nueva unidad. En LINDÓN, A. e HIERNAUX, D. (dirs.). Los giros de la Geografía Humana. Barcelona: Anthropos, 2010, p. 43-61.

ICOMOS. Carta Internacional del Turismo Cultural, 1999. [http://www.icomos.org/charters/tourism_sp.pdf]. (Consultado 27-06-2019).

INSTITUTO DEL PATRIMONIO CULTURAL DE EXPAÑA (IPCE). Plan Nacional de Paisaje Cultural. Madrid: Ministerio de Educación, Cultura y Deporte, 2015. [http://www.culturaydeporte.gob.es/planes-nacionales/planes-nacionales/paisaje-cultural.html]. (Consultado 27-06-2019).

MADERUELO, J. El paisaje. Génesis de un concepto. Madrid: Abada, 2013.

MANER, F. Spatial heritage and culture of the territory. En: MANERO, F. y GARCÍA CUESTA, J.L. (coords.). Territorial heritage and spatial planning. A geographical perspective. Pamplona: Thomson Reuters / Aranzadi, 2017, p. 29-56.

MARTÍNEZ DE PISÓN, E. El paisaje, patrimonio cultural. Revista de Occidente, 1997, No 194-195, p. 37-49.

MARTÍNEZ DE PISÓN, E. Paisaje, cultura y territorio. En: NOGUÉ, J. (ed). La construcción social del paisaje. Madrid: Biblioteca Nueva, 2007, p. 325-337.

MARTÍNEZ DE PISÓN, E. Sobre la idea y enseñanza del paisaje. Nimbus, 2012, No 29-30, p. 373-380.

MARTÍNEZ DE PISÓN, E. y ORTEGA, N. (eds.). La recuperación del paisaje. Madrid: Universidad Autónoma de Madrid y Fundación Duques de Soria, 2008.

MATA, R. El paisaje, patrimonio y recurso para el desarrollo territorial sostenible. Conocimiento y acción pública, Arbor, 2008, Vol. 184, № 729, p. 155-172.

MATA, R. Paisajes para un desarrollo sustentable y participativo. Revista Urbano, 2014, № 30, p. 8-21.

MATA, R. El Plan Nacional de Paisaje Cultural. Una iniciativa para el conocimiento, la cooperación y la salvaguarda de paisajes de alto interés cultural. En: FUNDICOT (ed.). Nuevos tiempos, nuevos objetivos. Fuerteventura: Gobierno de Canarias y Otros, 2016, p. 545-560. 
MATA, R. (coord.). El Paisaje. En: IGN (Instituto Geográfico Nacional). España en mapas. Una síntesis geográfica. Madrid, Centro Nacional de Información Geográfica, 2018, p. 479-498.

MATA, R. y SANZ, C. (eds.) Atlas de los Paisajes de España. Madrid: Ministerio de Medio Ambiente, 2003.

MATA, R. y TARROJA, A. (coords.). El paisaje y la gestión del territorio. Criterios paisajísticos en la ordenación del territorio y el urbanismo. Barcelona: Diputación de Barcelona, 2006.

MATA, R.; MEER LECHA-MARZO, A. de y PUENTE, L. de la. Sustainable development and maiking of territory and everiday landscapes as heritage. An experience in the Cantabria mountains. En: FERIA, J.M. (ed.): Territorial heritage and development. Paisajes Bajos: Taylor and Francis, 2012, p. 141-159.

MÍNGUEZ, C. Planificación y gestión turística de destinos patrimoniales: el caso del Real Sitio de San Lorenzo del Escorial. Anales de Geografía de la Universidad Complutense de Madrid, 2007, No 27, p. 82-102.

MOLINERO, F. y TORT, J. (coords.): Paisajes Patrimoniales de España. Madrid: Ministerio de Agricultura y Pesca, Alimentación y Medio Ambiente, 2018.

MULERO, A. Significado y tratamiento del paisaje en las políticas de protección de espacios naturales en España. Boletín de la Asociación de Geógrafos Españoles, 2013. № 62, p. 129-165.

MULERO, A. Hacia la gestión integrada del patrimonio en clave territorial: un análisis crítico a partir de la experiencia andaluza. Investigaciones Geográficas, 2015, № 63, p. 69-84.

MUÑOZ, J. Paisaje y geosistema. Una aproximación desde la Geografía Física. En MARTíNEZ DE PISÓN, E. (dir.). Paisaje y Medio Ambiente. Valladolid: Universidad de Valladolid y Fundación Duques de Soria, 1998, p. 45-56.

MUÑOZ, J. El orden natural del paisaje. En: ORTEGA CANTERO, N. (ed.). Naturaleza y cultura del paisaje. Madrid: Ediciones de la Universidad Autónoma de Madrid y Fundación Duques de Soria, 2004, p. 37-52.

MUÑOZ, J. El paisaje: tipos y unidades. En: PILLET, F.; CAÑIZARES, M.C. y RUIZ PULPÓN, A.R. (eds.) Territorio, paisaje y sostenibilidad. Un mundo cambiante. Barcelona: Ediciones del Serbal, 2010, p. 139-156.

NOGUÉ i FONT, J. (ed). La construcción social del paisaje. Madrid: Biblioteca Nueva, 2007, p. 11-24.

NOGUÉ i FONT, J. El retorno al paisaje. Enrahonar, 2010, No 45, p. 123-136.

OJEDA, J.F. Lectura transdiciplinar de paisajes cotidianos, hacia una valoración patrimonial. Método de aproximación. Revista Invi, 2013, Vol. 2, No 78, p. 25-75. 
ORTEGA, N. (coord.) Naturaleza y cultura del paisaje. Madrid: Universidad Autónoma de Madrid y Fundación Duques de Soria, 2004.

ORTEGA, N. Paisaje e Identidad. La visión de Castilla como paisaje nacional (1876-1936). Boletín de la Asociación de Geógrafos Españoles, 2009, № 51, p. 25-49.

ORTEGA, N. El lugar del paisaje y su valoración en la geografía española moderna: de Rafael Torres Campos a Manuel de Terán. Estudios Geográficos, Vol. 77, 2016, № 281, p. 595-617.

ORTEGA, J. El Patrimonio Territorial: el territorio como recurso cultural y económico. Ciudades, $1998, N^{\circ} 4$, p. 33-48.

PANAREDA, J. M. Introducciò a la Ciència del Paisatge. Documents d'Estudi EQUIP, 1979, № 1, p. 5-49.

PILLET, F. El turismo de interior en la España peninsular: el patrimonio territorial como destino turístico. Boletín de la Asociación de Geógrafos Españoles, 2012, № 59, p. 345-366.

PILLET, F. El paisaje literario y su relación con el turismo cultural. Cuadernos de Turismo, 2014, No 33, p. 297-309.

PILLET, F. La evolución de la imagen literaria del paisaje urbano: de la ciudad moderna a la ciudad actual. Estudios Geográficos, 2015, vol. 76, № 278, p. 285-307.

PRATS, L. La mercantilización del patrimonio: entre la economía turística y las representaciones identitarias. PH Boletín del Instituto Andaluz de Patrimonio Histórico, 2006, No 58, p. 72-80.

PRATS, L. El patrimonio en tiempos de crisis. Revista Andaluza de Antropología, 2012, № 2, p. 6885. [http://asana-andalucia.org/revista/uploads/raa/n2/lprats.pdf]. (Consultado 27-06-2019).

SABATÉ BEL, J. Paisajes culturales. El patrimonio como recurso básico para un nuevo modelo de desarrollo. Urban, 2004, No 9, p. 8-29.

SABATÉ BEL, J. De la preservación del patrimonio a la ordenación del paisaje. Intervenciones en paisajes culturales en Iberoamérica. En: HUAMANÍ MOSQUEIRA, M.S. (coord.). Paisajes culturales: comprensión, protección y gestión. Madrid: Agencia Española de Cooperación, 2011, p. 10-22.

SANTOS, M. A natureza do espaço. Sao Paulo: Huitec, 1996.

SANZ, C. Paisaje y Patrimonio Natural y Cultural: historia y retos actuales. Nimbus, 2012. No 29-30, p. 687-700.

SILVA, R. Agricultura, paisajes y patrimonio territorial. Los paisajes de la agricultura vistos como patrimonio. Boletín de la Asociación de Geógrafos Españoles, 2009, № 49, p. 309-334. 
SILVA, R. Paisaje, patrimonio y territorio. Algunos apuntes desde la perspectiva geográfica española. En COMITÉ ESPAÑOL DE LA UGI. Crisis, globalización y desequillibrios sociales y territoriales en España. Madrid: Instituto Geográfico Nacional / Centro Geográfico del Ejército / Asociación de Geógrafos Españoles / Real Sociedad Geográfica, 2016, p. 56-64.

SILVA, R. y FERNÁNDEZ, V. El nuevo paradigma del patrimonio y su consideración con los paisajes: Conceptos, métodos y prospectivas. Documents d'Anàlisi Geogràfica, 2017a, Vol. 63, No 1, p. 129-151.

SILVA, R. y FERNÁNDEZ, V. The limitess concept: the new heritage paradigm and its relation to space. En: MANERO, F. y GARCÍA, J.L. (coords.) Territorial heritage and spatial planning. A geographical perspective. Pamplona: Thomson Reuters Aranzadi, 2017b, p. 57-84.

SILVA, R.; FERNÁNDEZ, V. y MATA, R. Concepto, ámbito y significado de los paisajes patrimoniales. En: MOLINERO, F. y TORT, J. (coords.): Paisajes Patrimoniales de España. Madrid: MAPAMA, 2018, p. 13-34.

TROITIÑO, M.A. Patrimonio arquitectónico, cultura y territorio. Ciudades, 1998, № 4, p. 95-104.

TROITIÑO, M.A. El patrimonio cultural territorial y los retos de puesta en valor y uso turístico responsable. En: AGUILÓ, E. y ANTÓN, S. (eds.). 20 retos para el turismo en España. Madrid: Ediciones Pirámide, 2010, p. 261-278.

UNESCO. Recomendación sobre el Paisaje Urbano Histórico (2011). [http://portal.unesco.org/es/ ev.php-URL_ID=48857\&URL_DO=DO_ TOPIC\&URL_SECTION=201.html]. (Consultado 27-06-2019).

UNIÓN EUROPEA (UE). Estrategia Territorial Europea. Bruselas, 1999. [http://ec.europa.eu/regional_policy/sources/docoffic/official/reports/pdf/sum_es.pdf]. (Consultado 27-06-2019).

UNIÓN EUROPEA. Dictamen del Comité de las Regiones Europeo “Hacia un enfoque integrado del Patrimonio Cultural europeo". [http://eur-lex.europa.eu/legal-content/ES/TXT/?uri=CELEX\%3 A52014IR5515]. (Consultado 27-06-2019).

URQUIJO, P.S. y BOCCO, G. Pensamiento geográfico en América Latina: retrospectiva y balances generales. Investigaciones Geográficas, 2016, № 90, p. 1-18.

ZÁRATE, A. Paisajes culturales urbanos, entre la protección y la destrucción. Boletín de la Asociación de Geógrafos Españoles, 2011, № 57, p. 175-194.

ZÁRATE, A. Paisaje, forma y turismo en ciudades históricas. Estudios Geográficos, 2012, Vol. 73, No 273, p. 657-694.

ZOIDO, F. Territorio y Paisaje, conocimientos, estrategias y políticas. En: PILLET, F.; CAÑIZARES, M.C. y RUIZ PULPÓN, A.R. (eds.) Territorio, paisaje y sostenibilidad. Un mundo cambiante. Barcelona: Ediciones del Serbal, 2010, p. 85-112. 
ZOIDO, F. El Paisaje, un concepto útil para relacionar ética, estética y política. Scripta Nova. Revista Electrónica de Geografía y Ciencias Sociales, 2012, Vol. 16, № 407 [http://www.ub.edu/geocrit/ sn/sn-407.htm].

ZOIDO, F. y VENEGAS, C. (coords.). Paisaje y ordenación del territorio. Sevilla: Fundación Duques de Soria y Consejería de Obras Públicas y Transportes, 2002.

ZOIDO, F. y GÓMEZ, J. (coords.). Paisaje y Ordenación del Territorio. Banco de buenas prácticas en Geografía. Madrid: Colegio de Geógrafos, 2003. 